\title{
ИНФОРМАЦИОННЫЕ СИСТЕМЫ ДЛЯ МОНИТОРИНГА ПРИРОДНО-КЛИМАТИЧЕСКИХ УСЛОВИЙ АРКТИКИ
}

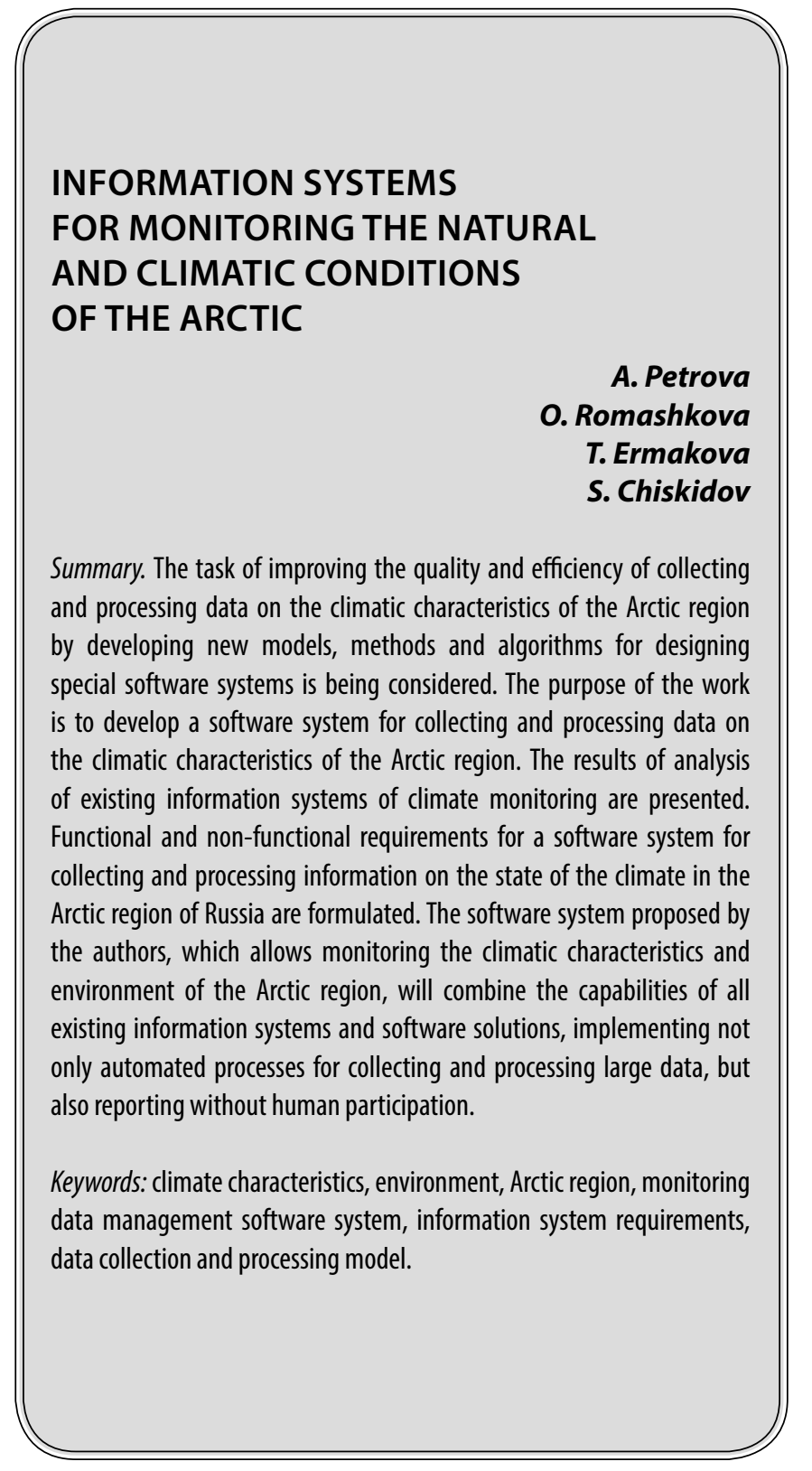

\section{Введение}

$\mathbf{H}$ а сегодняшний день всё более значимый интерес для экономики и науки среди территорий Российской Федерации вызывают северные регионы России и Арктики. Это объясняется экстремальными природно-климатическими условиями в регионе, включая сильные ветры, наличие ледяного покрова на арктических морях, низкие температуры воздуха.
Петрова Алина Михайловна

Аспирант, ГАОУ ВО «Московский городской педагогический университет (МГПУ)», г. Москва dom760@yandex.ru

Ромашкова Оксана Николаевна

Д.т.н., профессор, Российская академия народного хозяйства и государственной службы при Президенте РФ (РАНХИГС), г. Москва

ox-rom@yandex.ru

Ермакова Татьяна Николаевна К.т.н., дочент, ГАОУ ВО «Московский городской педагогический университет (МГПУ)», г. Москва

ermaktat@bk.ru

чискидов Сергей Васильевич

К.т.н., доцент, ФГБВОУ ВО «Академия гражданской защиты МЧС России» chis69@mail.ru

Аннотация. Рассматривается задача повышения качества и эффективности сбора и обработки данных о климатических характеристиках арктического региона путем разработки новых моделей, методов и алгоритмов проектирования специальных программных систем. Целью работы является разработка программной системы сбора и обработки данных о климатических характеристиках арктического региона. Представлены результаты анализа существующих информационных систем мониторинга климата. Сформулированы функциональные и нефункциональные требования к программной системе сбора и обработки информации о состоянии климата в арктическом регионе России. Предложенная авторами программная система, позволяющая проводить мониторинг климатических характеристик и окружающей среды арктического региона, объединит возможности всех существующих информационных систем и программных решений, реализовав не только автоматизированные процессы сбора и обработки больших данных, но и формирование отчетности без участия человека.

Ключевые слова: климатические характеристики, окружающая среда, арктический регион, программная система управления данными мониторинга, требования к информационной системе, модель сбора и обработки данных.

В настоящее время проблема мониторинга климата и окружающей среды достаточно остро стоит перед многими странами мира, в частности, и перед Российской Федерацией. На данный момент наблюдаются массовые попытки проектирования специализированных программных систем. Но разработка эффективных программных систем управления данными мониторинга климата и окружающей среды является достаточно сложной и комплексной задачей, требующей научного 
исследования и обоснования решений [1]. Она требует глубокого изучения опыта и процесса создания специализированных программных средств. Для того чтобы решить эту задачу, требуется определить трудности мониторинга климата и окружающей среды, провести оценку существующих моделей, методов и алгоритмов проектирования программных систем управления данными мониторинга климата и окружающей среды [2-4].

Важность изучения данной проблемы характеризуется такими причинами, как:

- необходимость создания новых и усовершенствования существующих методов, моделей, алгоритмов проектирования программных систем управления данными мониторинга климата и окружающей среды;

- высокая эффективность современных космических методов и технологий для разработки программных систем управления данными мониторинга климата и окружающей среды.

Проблемам исследования автоматизированного мониторинга состояния климата и окружающей среды посвящены труды многих российских и зарубежных ученых. Наибольший интерес представляют работы А.В. Базарова «Автоматизированная информационная система мониторинга территориального распределения общего содержания озона по данным всемирного банка TOMS», В.Ю. Волкова «Разработка автоматизированной системы экологического мониторинга на базе информационных технологий удаленного доступа», В.Н. Копылова «Разработка программно-технологического комплекса регионального центра космического мониторинга окружающей среды», А.А. Гостевой «Методическое и информационное обеспечение региональных геоинформационных систем мониторинга природной среды».

Вопросами моделирования, алгоритмизации и проектирования комплексных программных систем для мониторинга природных и климатических условий занимались отечественные ученые Н.Н. Моисеев, Г.С. Поспелов, Н.П. Бусленко и ряд других. Концепцией, посвященной разработке и созданию отечественной системы для оперативного мониторинга окружающей обстановки в Арктике, занимался крупный исследователь в области наук о Земле, увлеченный изучением и постижением Арктики, академик Николай Павлович Лаверов.

Российский государственный гидрометеорологический университет (РГГМУ), находящийся в г. Санкт-Петербурге, считается одним из научно-образовательных центров, сотрудники которого работают над осуществлением программ и направлений, посвященных проблеме арктического региона, и выполняют работы, имеющие научно-исследовательскую и прикладную направлен- ности в области гидрометеорологии, контроля экологической ситуации, прогнозирования опасных гидрометеорологических ситуаций в Арктическом регионе [5]. Данная работа выполняется в рамках Федеральных целевых и Государственных программ Министерства образования и науки России, Министерства природы России, различных хозяйственно-договорных проектов. РГГМУ представляет собой многопрофильный инновационный учебный центр, занимающийся контролем и оценкой состояния экологии природной среды Арктической зоны России.

В данный момент над созданием систем сбора и обработки данных о различных показателях окружающей среды в северных регионах России и в Арктической зоне Российской Федерации работает научно-исследовательский институт «АЭРОКОСМОС», под руководством академика Российской Академии наук, профессора В.Г. Бондура, Федеральное государственное бюджетное учреждение «Арктический и Антарктический научно-исследовательский институт» (ФГБУ «ААНИИ»), Integrated Climate Data Center — ICDC.

Выполненный анализ научных трудов в рассматриваемой сфере позволил сделать вывод о наличии существенных проблем в вопросах автоматизации, алгоритмизации и моделирования систем управления данными мониторинга. На сегодняшний день отсутствует единая система сбора и обработки данных о климатических характеристиках арктического региона, которая позволила бы решить все поставленные задачи.

В силу этого актуальной проблемой является создание новых и усовершенствование существующих моделей, методов и алгоритмов проектирования программных систем для сбора и обработки данных о климатических характеристиках арктического региона.

Данная работа описывает решение одной из таких задач.

$$
\begin{aligned}
& \text { Функциональные залачи } \\
& \text { центра мониторинга } \\
& \text { климатических показателей }
\end{aligned}
$$

Комплекс наземных средств мониторинга подчиняется непосредственно заместителю генерального конструктора по радиотехническим системам и наземным комплексам. Во главе комплекса наземных средств мониторинга стоит начальник комплекса. Начальник комплекса непосредственно управляет отделами наземного комплекса управления, наземных станций и контрольной аппаратуры, и мониторинга. Комплекс наземных средств мониторинга в своей деятельности руководствуется действующей российской законодательной ба- 
зой, Уставом Общества, Положением, приказами и указами генерального директора и его заместителей.

Его основными задачами являются:

1. Создание наземных целевых комплексов управления, наземных целевых комплексов, создание имитационной аппаратуры для обеспечения проведения испытаний.

2. Изучение зарубежных аналогов и оценка технической новизны и технического уровня разработок.

3. Определение облика перспективных наземных комплексов.

4. Участие в выполнении научно-исследовательских и опытно-конструкторских работ по созданию космических комплексов и систем.

5. Организация и проведение испытаний наземных комплексов.

Отдел мониторинга является структурным подразделением комплекса наземных средств мониторинга.

Основные задачи отдела мониторинга:

1. Создание новых и модернизация действующих наземных целевых комплексов мониторинга и их составных частей, создаваемых в рамках выполнения научно-исследовательских и опытно-конструкторских работ по тематическим заказам.

2. Проведение авторского и технического надзора при создании наземных целевых комплексов мониторинга.

3. Обеспечение высокого технического уровня создаваемых наземных целевых комплексов мониторинга на основе последних достижений науки и техники.

4. Изучение процессов в атмосфере и океане.

5. Изучение непредсказуемости погоды и климата.

6. Изучение физических механизмов, формирующих структуру пограничного слоя атмосферы над сложной подстилающей поверхностью.

7. Оценка и анализ данных наблюдений.

Взаимодействие между должностными лицами происходит следующим образом. Генеральный директор ведет переговоры с организациями, которые тесно связаны с разработкой космических систем. Затем он дает поручения первым заместителям. Первые заместители заключают контракты с организациями и дают уже поручения каждому заместителю генерального конструктора по своим тематикам. Заместители генерального конструктора дают поручения по комплексам. Начальник комплекса осуществляет контроль производственной деятельности сотрудников, контролирует работу исполнителей по выполнению производственного задания в соответствии с распределением работ между ними. Начальник отдела организовывает и обеспечивает вы- полнение отделом научно-технических работ, связанных с разработкой, испытаниями и вводом в эксплуатацию наземных целевых комплексов мониторинга, обеспечивающих потребителей космическими данными с характеристиками, заданными в тактико-техническом задании.

Ведущий инженер-конструктор организует и планирует работы по конструированию объектов, занимается разработкой технических заданий на проектирование, технических предложений по разработке новых и улучшению существующих конструкций, эскизных и технических проектов, описывает технологии реализации проектно-конструкторских работ. Согласно разработанному техническому заданию, ведущий инженер-электроник подготавливает перечень необходимых технических средств для дальнейшей сборки вычислительной стойки. На основе вычислительной стойки и технического задания ведущему программисту предстоит разработка программной системы управления данными мониторинга климата и окружающей среды. Ведущий специалист мониторинга занимается заполнением климатических показателей в базу данных.

Оценка функциональных возможностей информационных систем для мониторинга климатических условий

На сегодняшний день в мировом пространстве существует множество различных информационных систем для контроля климата. К основным задачам, автоматизируемым с помощью данных систем, относятся: сбор и обработка информации, отображение результатов в виде формализованной отчетности управляющих программ $[6,7]$. Пользователи таких информационных систем имеют возможность в режиме реального времени оценивать многомерную обстановку в разных региональных зонах.

Авторами был выполнен анализ следующих информационных систем управления данными мониторинга климата: Arctic Regional Ocean Observing System (AROOS) (используется с 2006 г.), Svalbard Integrated Arctic Earth Observing System (SIAEOS) (на этапе разработки), комплекс программ комплекса программно-технических средств управления техническими средствами (КП (ЭЗ) КПТС УТС) космического аппарата «Электро» № 3 (КА «Электро» № 3) (с 2019 г.), специальное программное обеспечение управления техническими средствами КА «Арктика-М» (СПО УТС-АМ) (в стадии запуска) и др. [8, 9].

Миссия AROOS заключается в создании арктической информационной системы мониторинга Земли. Система предназначена для автоматизации процесса контроля основных параметров биологических, метеорологических, криосферных и геофизических процессов. К основным задачам, выполняемым системой, относятся: 
Таблица 1. Сравнительный анализ программных систем, используемых для мониторинга характеристик климата и окружающей среды

\begin{tabular}{|l|l|l|} 
Наименование ИС & Платформа & Основные функции и возможности \\
AROOS & C++ & $\begin{array}{l}\text { Мониторинг основных характеристик биологических, } \\
\text { метеорологических, криосферных, геофизических процессов }\end{array}$ \\
\hline SIAEOS & C++ & $\begin{array}{l}\text { Oперативный мониторинг и прогнозирование циркуляции водных масс } \\
\text { В Арктических регионах }\end{array}$ \\
\hline КП (ЭЗ) КПТС УТС & $\begin{array}{l}\text { Embarcadero RAD Studio (Delphi, } \\
\text { C++, C\#) }\end{array}$ & $\begin{array}{l}\text { Оперативный мониторинг поверхности Земли. } \\
\text { Прогноз погоды в ручном режиме. } \\
\text { Мониторинг климата и глобальных изменений. }\end{array}$ \\
\hline
\end{tabular}

1. Унифицирование создания и функционирования каталогов и доступа ко всем данным дистанционного зондирования Земли;

2. Выдача доступа к временному ряду определений спутниковой информации в рамках деятельности системы;

3. Обеспечение полевых работ в рамках функционирования системы требующейся информацией, получаемой со спутника.

Система SIAEOS используется с целью развития и поддержания оперативного наблюдения и предсказания движения океана, масс воды, состояния поверхности океана, морского льда и биологических/химических элементов океана $[8,10]$. Благодаря данной системе аналитик получает доступ к картам скоплений льда в Арктике, региональным ледовым картам, картам льда для Гренландии и Арктики, глобальным ледовым картам скопления, плотности и типа морского льда, кромки льда, информации об общей суточной площади морского льда в Арктике, глобальном и региональном скоплении льда, толщине льда на изучаемой территории, глобальном ледовом дрейфе, временных рядах за последние 20 лет с ежедневным обновлением.

Система обладает универсальным пользовательским интерфейсом, а пользователь обеспечен доступом ко всем типам данных в хранилище [11].

КП (ЭЗ) КПТС УТС является управляющей программой мониторинга климата и окружающей среды. Она принимает, обрабатывает, архивирует и распространяет информацию, получаемую с КА «Электро-Л» № 3, в заинтересованные ведомства Российской Федерации.

На основе этой информации определенные научно-исследовательские центры в режиме реального времени могут спрогнозировать погоду в субъектах Российской Федерации. Основным предназначением КА «Электро-Л» № 3 является:

1. Синоптическая оценка и прогноз погоды;
2. Оценка и прогноз положения, в котором находятся акватории морей и океанов;

3. Оценка и прогноз гелиогеофизического положения на околоземных космических просторах;

4. Контроль климата и широкомасштабных изменений;

5. Мониторинг чрезвычайных ситуаций;

6. Обеспечение охраны окружающей среды и др.

В таблице 1 представлены сводные результаты анализа существующих программных систем, используемых для мониторинга характеристик климата и окружающей среды.

На основе проведенного сравнительного анализа авторами была предложена новая программная система сбора и обработки данных о климатических характеристиках арктического региона (ПСМ КОСАР).

ПСМ КОСАР должна удовлетворять следующим основным функциональным требованиям:

1. автоматизировать ведение базы данных о полученных исходных характеристиках климата и окружающей среды;

2. выполнять автоматизированное прогнозирование численных значений характеристик климата и окружающей среды на основе мониторинга поверхности Земли;

3. автоматизировать выполнение мониторинга окружающей среды;

4. автоматизировать формирование отчетности о результатах мониторинга климата и окружающей среды.

Для проектирования и создания ПСМ КОСАР необходимы следующие программные средства:

\section{Серверная часть:}

- СУБД Microsoft SQL Server Management Studio;

- CA ERWin Process\&Data Modeler;

- Bizagi Process Modeler. 


\section{Клиентская часть}

\section{Операционная система Microsoft Windows 10}

ПСМ КОСАР взаимодействует с Федеральным государственным бюджетным учреждением «Научно-исследовательский центр космической гидрометеорологии «Планета», Федеральным государственным бюджетным учреждением «Институт прикладной геофизики имени академика Е.К. Федорова» для сбора сведений, данных, характеристик.

Процесс мониторинга включает в себя шесть последовательных этапов:

1. Идентификация или выбор из перечня показателей мониторинга;

2. Контроль потенциальных ошибок, появляющихся в ходе проведения наблюдений;

3. Определение места для осуществления наблюдений;

4. Установление временных рамок и повторяемости проведения наблюдений;

5. Фиксация наблюдений;

6. Первоначальная обработка данных и их хранение.

Идентификация или выбор из перечня показателей мониторинга. Выбор из списка параметров мониторинга является важным условием для сбора и обработки данных о климатических характеристиках. В данном шаге необходимо определить по каким показателям будет происходить мониторинг климата и окружающей среды в ПСМ КОСАР.

Перечень измеряемых показателей:

1. Температура;

2. Атмосферное давление;

3. Направление ветра;

4. Скорость ветра;

5. Влажность воздуха;
6. Атмосферные осадки;

7. Облачность атмосферы.

Учет возможных ошибок, возникающих во время наблюдений. Существуют систематические ошибки, обусловленные самими измерениями. Если мы будем заниматься измерением сами, взяв в руки термометр, то наши показатели будут недостаточно точными. Поэтому следует измерения получать от проверенных источников, а не проводить самим.

Определение места для осуществления наблюдений. Самым главным требованием, касающимся определения места, является то, что там должны отсутствовать сильные, непредвиденные, направленные факторы, кардинальным образом искажающие результаты наблюдений. Это является довольно сложной задачей в условиях Арктики.

Регистрация наблюдений. Основным методом регистрации наблюдений будет ведение базы данных.

Первичная обработка данных и их «складирование». Проводится проверка ведения базы данных на наличие ошибок, повторов записей.

\section{Зак^ючение}

Авторами выполнен анализ результатов исследований в области сбора и обработки данных о климатических характеристиках арктического региона и получена оценка функциональных возможностей существующих информационных систем для мониторинга климатических условий с учетом особенностей их применения в арктическом регионе.

Предложена программная система сбора и обработки данных о природно-климатических характеристиках арктического региона, разработаны функциональные требования и требования к серверной и клиентской частям программной системы.

\section{ЛИТЕРАТУРА}

1. Ромашкова 0.Н., Федин Ф.О., Ермакова Т.Н. Нейросетевая компьютерная модель для поддержки принятия решений в образовательных комплексах // Вестник Рязанского государственного радиотехнического университета. 2017. № 61. С. 54-59.

2. Ромашкова 0.Н., Ермакова Т.Н. Этапы реализации методики выбора информационной модели для оценки показателей качества обучения // Междисциплинарные исследования в области математического моделирования и информатики Материалы 7-й научно-практической internet-конференции. отв. ред. Ю.С. Нагорнов. 2016. С. 318-321.

3. Ромашкова 0.Н., Ермакова Т.Н. Мониторинг качества образования в средней общеобразовательной организации с использованием современных средств информатизации // Вестник Российского университета дружбы народов. Серия: Информатизация образования. 2014. № 4. С. 10-17.

4. Ромашкова 0.Н., Ермакова Т.Н. Методика выбора информационной модели для оценки показателей качества обучения // Вестник Российского университета дружбы народов. Серия: Информатизация образования. 2015. № 2. С. 14-20.

5. Ромашкова 0.Н., Яковлев Р.И. Анализ моделей и методов для оценки живучести инфокоммуникационных сетей в условиях чрезвычайных ситуаций // T-Comm: Телекоммуникации и транспорт. 2012. Т. 6. № 7. С. 165-170. 
6. Ромашкова 0.Н., Ермакова Т.Н. Моделирование информационных процессов управления образовательным комплексом // Вестник Российского университета дружбы народов. Серия: Информатизация образования. 2014. № 2. С. 122-129.

7. Gaidamaka Y.V., Romashkova 0.N., Ponomareva L.A., Vasilyuk I.P. Application of information technology for the analysis of the rating of university // B c6орнике: CEUR Workshop Proceedings 8. Cep. "ITTMM 2018 — Proceedings of the Selected Papers of the 8th International Conference "Information and Telecommunication Technologies and Mathematical Modeling of High-Tech Systems'"'. 2018. C. 46-53.

8. Romashkova 0.N., Ponomareva L.A., Chiskidov S.V. Instrumental implementation of the educational process model to improve the rating of the universities // CEUR Workshop Proceedings 8. Cep. "ITTMM 2019 - Proceedings of the Selected Papers of the 8th International Conference "Information and Telecommunication Technologies and Mathematical Modeling of High-Tech Systems'"' 2019. C. 92-101

9. Официальный сайт Arctic Regional Ocean Observing System. [Электронный ресурс].— Режим доступа: URL: https://arctic-roos.org/node/92 (10.10.2020).

10. Официальный сайт SIAEOS. [Электронный ресурс].— Режим доступа: URL: https://cordis.europa.eu/project/id/261747 (11.10.2020).

11. Ромашкова 0.Н., Ломовцев Р.С., Пономарева Л.А. Компьютерная поддержка принятия управленческих решений для образовательной системы регионального уровня // Вестник Рязанского государственного радиотехнического университета. 2019. № 67. С. 50-58.

( Петрова Алина Михайловна ( dom760@yandex.ru ), Ромашкова Оксана Николаевна ( ox-rom@yandex.ru ),

Ермакова Татьяна Николаевна ( ermaktat@bk.ru), Чискидов Сергей Васильевич ( chis69@mail.ru).

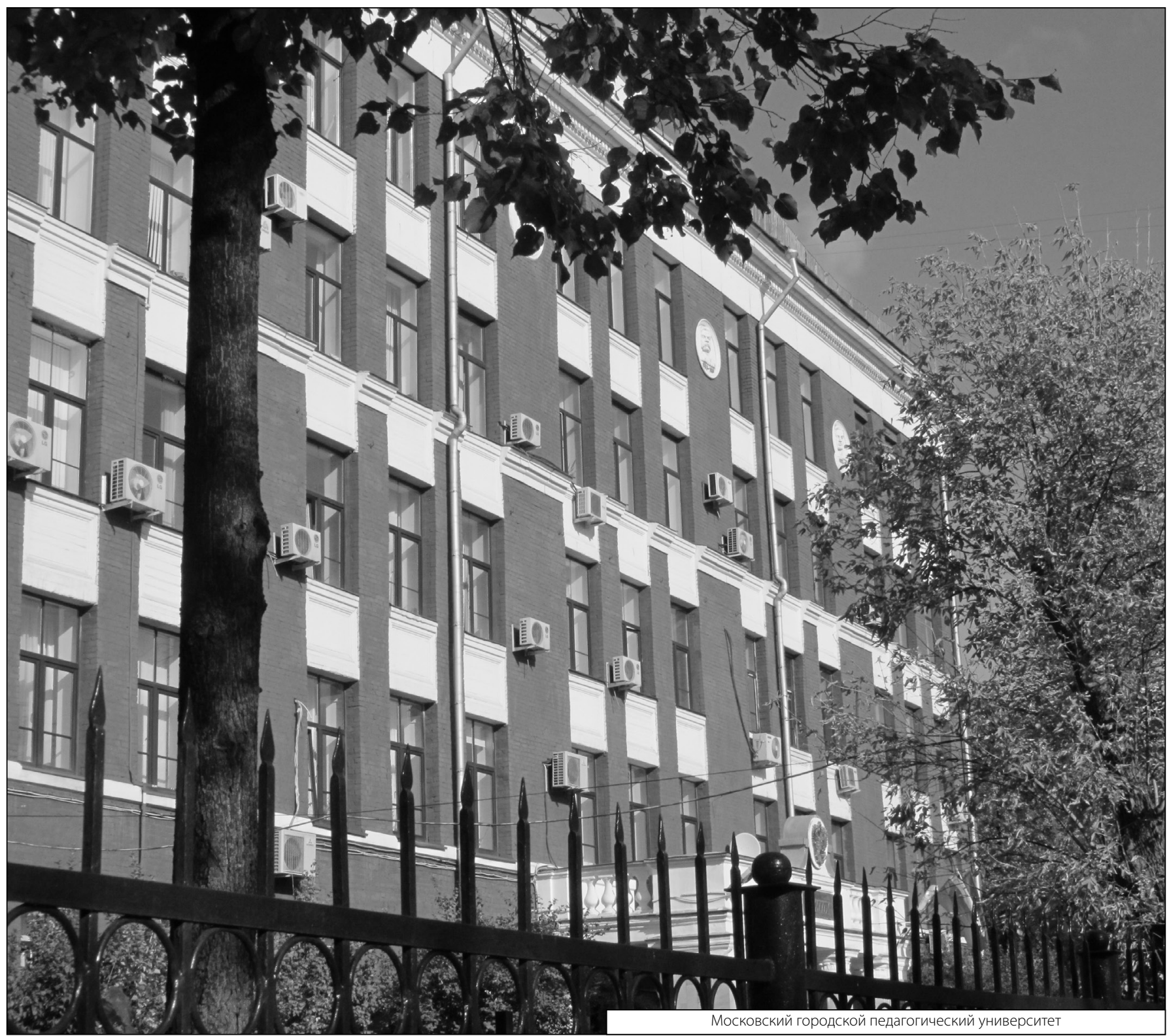

